\title{
Comparative Study of the Effects of Processing on the Carotenoid Composition of Chinese (Thea sinensis) and Assamese (Thea assamica) Tea
}

\author{
Shyamala Venkatakrishna, B. R. Premachandra and H. R. Cama \\ Department of Biochemistry, Indian Institute of Science, \\ Bangalore, Karnataka 560 012, India \\ Received June 7, 1976
}

\begin{abstract}
A comparative study of the effects of processing on the carotenoid composition of the two popular varieties of tea namely, Thea sinensis and Thea assamica has been carried out. The results show that the carotenoid pattern in tea dust is very similar to that in tea leaves in spite of the drastic manufacturing conditions. However, about $20 \%$ of the carotenoids are found to be lost during manufacture. Also, the carotenoid loss during tea preparation has been carried out. The results reveal that about $10 \%$ of the carotenoids are lost from the tea dust during tea brewing.
\end{abstract}

Tea is a perennial evergreen shrub belonging to the Camellia genus of the Theaceae family. On taxonomical basis, tea could be classified into two distinct varieties:- Thea sinensis, Thea assamica.

The first and the second leaves which are the youngest termed the 'tea bud' are employed for the manufacture of good quality tea. The conventional process of tea manufacture from green tea leaves involves four major steps, namely whithering, rolling, fermentation and firing. ${ }^{1)}$ Several biochemical transformations take place during these processes which account for the development of excellent flavour. The flavour components of black tea have been shown to contain geraniol, $\beta$ ionone, linalool and its oxides. ${ }^{2,3}$ In view of the extreme lability of carotenoids which constitute one of the major parts of chief pigments in the tea bud, it could be anticipated that they undergo decomposition during the drastic conditions of tea manufacture. Further, it has been reported that carotenoids are involved in the formation of aroma components of tea. ${ }^{4 \sim 7}$

Hence, it would be of interest to study the nature and extent of degradation of carotenoids during tea manufacture.

The present paper includes a comparative study of the carotenoid composition of tea buds of the two distinct varieties namely, Thea sinensis and Thea assamica, widely used in the world to-day and investigates the carotenoid composition of tea dust from these two varieties in order to evaluate the extent of degradation during conditions of tea manufacture. The study also involves the changes in the pigment composition occurring in the tea dust during the preparation of tea drink.

\section{MATERIALS AND METHODS}

The tea buds and the tea dusts of the two varieties namely, Thea assamica and Thea sinensis were obtained from Sirikundra estate, Coonoor, South India, where the tea manufacturing was carried out by the conventional method.*

\section{Methods}

Extraction of carotenoids. For comparative study of tea buds and dust, $50 \mathrm{~g}$ of tea leaves were soaked in about $100 \mathrm{ml}$ methanol. They were blended for two minutes in a Waring blender and filtered. The residue was repeatedly extracted successively with acetone and peroxide-free diethylether. The total extract was washed with water and the diethylether layer was evaporated to dryness in vacuo. In order to remove

* The samples of leaves and dusts were obtained fresh during the month of September. The dusts of both the varieties were manufactured using the leaves employed for the present studies. 
chlorophyll and fats, this extract was refluxed with $10 \%$ methanolic potassium hydroxide $(50 \mathrm{ml})$ for $20 \mathrm{~min}$ at $50 \sim 60^{\circ} \mathrm{C}$ under a stream of nitrogen and left overnight at room temperature. Carotenoids were extracted after saponification with peroxide-free diethylether. Diethylether layer was washed free of alkali and reduced in vacuo to dryness, taken in small amounts of light petrol $\left(40 \sim 60^{\circ} \mathrm{C}\right)$ and subjected to chromatographic separation.

The carotenoids from tea dust were similarly extracted.

Separation, characterization and estimation of carotenoids. The carotenoid extract taken in petrol was subjected to alumina column chromatography. The individual bands were separated by gradient elution employing peroxide-free diethylether and petrol, and acetone-petrol mixtures as described earlier. ${ }^{8)}$

The individual bands were tentatively identified by their adsorption behaviour as well as their visible absorption spectra as recorded by Cary-14 recording spectrophotometer. ${ }^{\theta)}$ The epoxides were characterized by the ethanolic hydrogen chloride test. ${ }^{10)}$

The estimation of carotenoid was carried out by using the $E_{1 \mathrm{~cm}}^{1 \%}$ values of the authentic compounds. ${ }^{11}$

Finally, the identity of each carotenoid was confirmed by co-chromatography with authentic samples on thin layers of silica and alumina.

The authentic samples were isolated from the natural sources mentioned in Table I or chemically synthesized as per the procedures already described in literatures. The pertinent references for each carotenoid has been denoted in the last column of Table I. $\alpha$-and $\beta$ Carotene were gifts from Hoffmann La Roche.

Experiments to study the changes of carotenoid compositions in tea dust during the preparation of tea drink:-

About $0.5 \mathrm{~g}$ of tea dust was accurately weighed into a $100 \mathrm{ml}$ beaker, to which $50 \mathrm{ml}$ of boiling water was added. It was boiled further (along with the dust) for two minutes and then allowed to stand for five minutes. The tea residue was rapidly filtered off and the carotenoid in the residue was extracted by the similar procedure outlined earlier. As a control, for comparison same quantity of tea dust was accurately weighed into a beaker and allowed to stand for seven minutes in cold water, residue filtered and analysed for carotenoid composition. The effect of conditions of tea-drink preparation on tea dust carotenoids has been worked on both the varieties of tea.

Carotenoid extraction from tea drink. The carotenoids, in the tea drink were extracted as follows:

To the filtrate obtained, equal volume of acetone was added along with $50 \mathrm{ml}$ of diethylether. The carotenoids and chlorophylls obtained in diethylether layer were concentrated and saponified as described earlier.
The total carotenoids obtained after saponification were estimated by their visible absorption spectra.

\section{RESULTS AND DISCUSSION}

Table I describes the carotenoid distribution in Chinese and Assamese tea leaves and dust. As could be seen from the Table I, in the sample that we have analysed, the carotenoid content of Chinese tea leaves is nearly twice that of the Assamese variety. Also considering the carotene to xanthophyll ratios, Chinese variety seems to accumulate more of carotenes than xanthophylls in contrast to Assamese variety. However, in both the varieties $\beta$-carotene forms the bulk of carotene fraction whereas lutein forms the bulk of xanthophyll fraction. This may be due to the fact that much of the $\alpha$ carotene formed may be hydroxylated to lutein whereas very little of the $\beta$-carotene formed might be getting converted to corresponding xanthophylls.

$\alpha$-Carotene is found in significantly higher amounts in Chinese variety than in Assamese. However, $\beta$-zeacarotene, $\xi$-carotene and phytofluene could be identified only in trace amounts in both the varieties. Of particular interest is the detection of cryptoxanthin and its epoxides. These may well be the precursors in the formation of dihydroxy, diepoxy xanthophylls like violaxanthin, luteoxanthin etc., in leaves. The value of violaxanthin in the Chinese leaves is found to be less than that of neoxanthin in Table I, while the reverse is found to be true in case of Assamese leaves. This may be due to any of the following reasons:- (a) the observed discrepancy is a reflection of varietal difference, or, (b) there may be an experimental error involved in the estimation of violaxanthin in the Chinese variety.

Due to inaccessibility to the same source we were unable to check this point again.

Analysis of carotenoid composition of dust reveals a close semblance to that of leaves. It is surprising to find, especially in view of the extreme lability of carotenoids that most of the carotenoids detected in tea leaf could be detected in dust also. As in leaves $\beta$-carotene 
Table 1. Carotenoid Analysis of Chinese and Assamese leaves and Dust.

\begin{tabular}{|c|c|c|c|c|c|}
\hline \multirow[t]{2}{*}{ Carotenoids } & \multicolumn{2}{|c|}{ Chinese } & \multicolumn{2}{|c|}{ Assamese } & \multirow[t]{2}{*}{ Source reference } \\
\hline & Leaf & Dust & Leaf & Dust & \\
\hline Phytofluene & Traces & Traces & Traces & Traces & Tomato $^{(\delta)}$ \\
\hline a-Carotene & $\begin{array}{l}2.10^{a)} \\
(3.25)\end{array}$ & $\begin{array}{c}0.10 \\
(0.20)\end{array}$ & $\begin{array}{c}0.19 \\
(0.63)\end{array}$ & $\begin{array}{c}0.05 \\
(0.20)\end{array}$ & $\begin{array}{l}\text { Authentic } \\
\text { sample obtained }\end{array}$ \\
\hline$\beta$-Carotene & $\begin{array}{c}21.66 \\
(33.57)\end{array}$ & $\begin{array}{l}17.60 \\
(35.55)\end{array}$ & $\begin{array}{r}6.48 \\
(21.57)\end{array}$ & $\begin{array}{c}4.95 \\
(20.09)\end{array}$ & $\begin{array}{l}\text { from Hoffmann } \\
\text {-La Roche, Basle }\end{array}$ \\
\hline$\beta$-Zeacarotene & $\begin{array}{c}0.24 \\
(0.37)\end{array}$ & $\begin{array}{c}0.08 \\
(0.16)\end{array}$ & $\begin{array}{l}1.95 \\
(6.49)\end{array}$ & $\begin{array}{c}0.15 \\
(0.60)\end{array}$ & - \\
\hline Carotene & Traces & Traces & $\begin{array}{c}0.08 \\
(0.26)\end{array}$ & $\begin{array}{c}0.06 \\
(0.24)\end{array}$ & Tomato $^{15)}$ \\
\hline Aurochrome & $\begin{array}{c}0.09 \\
(0.13)\end{array}$ & Traces & $\begin{array}{l}0.08 \\
(0.26)\end{array}$ & Traces & Synthesized ${ }^{16)}$ \\
\hline Mutatochrome & $\begin{array}{r}0.18 \\
(0.27\end{array}$ & $\begin{array}{c}0.38 \\
(0.76)\end{array}$ & $\begin{array}{c}0.04 \\
(0.13)\end{array}$ & Traces & - \\
\hline Cryptoxanthin & $\begin{array}{c}2.43 \\
(3.76)\end{array}$ & Traces & $\begin{array}{c}0.36 \\
(1.19)\end{array}$ & $\begin{array}{c}0.50 \\
(2.03)\end{array}$ & Oranges $^{17)}$ \\
\hline Cryptoflavin & $\begin{array}{c}0.09 \\
(0.13)\end{array}$ & $\begin{array}{c}0.32 \\
(0.64)\end{array}$ & $\begin{array}{c}0.42 \\
(1.39)\end{array}$ & $\begin{array}{l}0.10 \\
(0.40)\end{array}$ & Synthesized ${ }^{18}$ \\
\hline $\begin{array}{l}\text { Cryptoxanthin-5, } \\
\text { 8-diepoxide }\end{array}$ & $\begin{array}{c}0.33 \\
(0.51)\end{array}$ & Traces & Traces & $\begin{array}{c}0.03 \\
(0.12)\end{array}$ & - \\
\hline $\begin{array}{l}\text { Lutein and } \\
\text { zeaxanthin }\end{array}$ & $\begin{array}{c}35.61 \\
(55.19)\end{array}$ & $\begin{array}{l}30.70 \\
(62.01)\end{array}$ & $\begin{array}{c}18.74 \\
(62.40)\end{array}$ & $\begin{array}{l}15.28 \\
(62.03)\end{array}$ & Gul Mohr' ${ }^{1 \theta)}$ \\
\hline Lutein-5: 6 epoxide & Traces & $\begin{array}{c}0.08 \\
(0.16)\end{array}$ & $\begin{array}{c}0.23 \\
(0.76)\end{array}$ & $\begin{array}{c}3.00 \\
(12.18)\end{array}$ & - \\
\hline Violaxanthin & $\begin{array}{c}0.12 \\
(0.18)\end{array}$ & $\begin{array}{l}0.08 \\
(0.16)\end{array}$ & $\begin{array}{l}1.05 \\
(3.49)\end{array}$ & Traces & T. stans flower ${ }^{20)}$ \\
\hline Luteoxanthin & Traces & Traces & $\begin{array}{c}0.20 \\
(0.66)\end{array}$ & $\begin{array}{c}0.10 \\
(1.62)\end{array}$ & - \\
\hline Neoxanthin & $\begin{array}{c}1.44 \\
(2.23)\end{array}$ & $\begin{array}{c}0.04 \\
(0.08)\end{array}$ & $\begin{array}{c}0.20 \\
(0.66)\end{array}$ & $\begin{array}{c}0.10 \\
(0.40)\end{array}$ & - \\
\hline $\begin{array}{l}\text { Total } \\
\text { Total losses }\end{array}$ & 65.67 & $\begin{array}{l}51.00 \\
{[22.30]}\end{array}$ & 30.20 & $\begin{array}{c}24.80 \\
{[17.88]}\end{array}$ & \\
\hline $\begin{array}{l}\text { Carotene } \\
\text { Carotene loss }\end{array}$ & 24.27 & $\begin{array}{c}18.16 \\
{[25.78]}\end{array}$ & 8.82 & $\begin{array}{c}5.21 \\
{[40.90]}\end{array}$ & \\
\hline $\begin{array}{l}\text { Xanthophyll } \\
\text { Xanthophyll loss }\end{array}$ & 40.02 & $\begin{array}{c}31.22 \\
{[21.98]}\end{array}$ & 21.20 & $\begin{array}{l}19.40 \\
{[8.4]}\end{array}$ & \\
\hline
\end{tabular}

a) Values indicate $\mathrm{mg} / 100 \mathrm{~g}$ dry wt.

The values in parentheses indicate $\%$ of the total carotenoids.

[ ] $\%$ loss of the carotenoids.

and lutein constitute the bulk of hydrocarbons and xanthophylls, respectively. In the material analysed the total carotenoid loss during manufacturing condition was significant being as much as $20 \%$.

The individual carotenoids seem to get decomposed to different degrees. ${ }^{12)}$ However, in view of the highly variable manufacturing conditions it would be significant to consider the losses involved in total carotene, $\beta$ carotene, total xanthophyll and lutein for the sake of comparison between the two varieties.
The carotene/xanthophyll content in Chinese variety falls from $24.2 / 40.2$ to $18.1 / 31.2$ and in Assamese variety it falls from $8.8 / 21.2$ to $5.2 /$ $19.4, i . e$, in both the varieties the hydrocarbon carotenoids decompose to a greater extent than the xanthophylls upon exposure to manufacturing conditions. However, it is quite probable that epoxyxanthophylls may be formed during the oxidative conditions of manufacture. And this may alter the quantitative picture of xanthophyll decomposition. As $\beta$-carotene constitutes the bulk of hydrocar- 
Table II. Carotenoid Loss in Tea Residues DURING TEA BREWING

The values quoted are the averages of the three samples $(500 \mathrm{mg})$ each estimated separately.

The values in parantheses indicate $\%$ loss of carotenoids.

\begin{tabular}{ccccc}
\hline \multirow{2}{*}{ Variety } & \multicolumn{3}{c}{$\mu \mathrm{g}$} \\
\cline { 3 - 5 } Chinese & $\begin{array}{c}\text { Total } \\
\text { carotenoids }\end{array}$ & $\begin{array}{c}\text { Hydro- } \\
\text { carbons }\end{array}$ & $\begin{array}{c}\text { Xantho- } \\
\text { phylls }\end{array}$ \\
\hline \multirow{4}{*}{$\begin{array}{c}\text { Control } \\
\text { Experi- } \\
\text { mental } \\
\text { Loss }\end{array}$} & 245 & 100 & 144 \\
Assamese & 227 & 94 & 83 \\
& $\begin{array}{c}\text { Control } \\
\text { Experi- } \\
\text { mental } \\
\text { Loss }\end{array}$ & 126 & 33 & 83 \\
& 117 & 31 & 76 \\
& $(6.7)$ & $(5.0)$ & $(8.3)$ \\
\hline
\end{tabular}

bon carotenes and, lutein-the xanthophylls, the total loss in both fractions is largely due to the decomposition of these two carotenoids.

It has been observed that carotenoid content of tea leaves is highly variable, ${ }^{13)}$ so also the manufacturing conditions. Therefore, the values quoted in Table I must be taken to reflect the qualitative changes.

In Table II the loss of carotenoid from the tea dust during tea preparation is given. As is evident from the data about $7 \%$ of the carotenoid loss takes place in both the varieties.

The xanthophyll loss is slightly greater than that of hydrocarbons. However, 90\% of the carotenoids in the tea dust are retained in the residue after tea preparation. This may appear surprising in view of the lability of carotenoids. However, it may well be due to the presence of antioxidants like polyphenols, catechols, etc., which protect carotenoids from decomposition. Since about $10 \%$ of the carotenoid content of tea dust was observed to be lost on brewing, the tea drink was analysed for the presence of any carotenoids in both experimental and control samples, as described under Methods. The analysis accounted for about $3 \mu \mathrm{g}$ of carotenoids in the experimental, which forms about $16 \%$ of the total carotenoids $(18 \mu \mathrm{g})$ lost from the tea dust. No carotenoid could be detected in the control tea drink. It is possible that the $84 \%$ of the unaccountable carotenoid
(15 $\mu \mathrm{g} / 500 \mathrm{mg}$ of tea dust) might have decomposed under the conditions of tea brewing. In view of the proposed observation that carotenoids are converted into aroma components during manufacture, ${ }^{12}{ }^{14)}$ it may well be that, the loss of carotenoids from the dust during tea brewing may also contribute towards flavour of tea. It would be of much greater significance to investigate the aroma components formed during the conditions of tea brewing, as they can be readily captured by the drink.

Acknowledgements. Authors thank Dr.C.S. Venkatram, Director, UPASI Tea Research Station, Cinchona (S. India), for having supplied the material for the above work. The all-trans $\beta$-carotene and $\alpha$ carotene were generous gifts from $M / S$ Hoffmann -La Roche, Basle. The technical assistance of Miss R. V. Jayamma and Mr. C. Venkateshan, as well as the financial support from the C. S. I. R. (India), are gratefully acknowledged.

\section{REFERENCES}

1) M. L. Bokuchava and N. I. Skobeleva, $A d v$. Food Res., 17, 243 (1969).

2) T. Yamanishi, A. Kobayashi, H. Nakamura, A. Uchida, S. Mori, K. Ohsawa and S. Sakakura, Agr. Biol. Chem., 32, 379 (1968).

3) S. Sato, S. Sasakura, A. Kobayashi, Y. Nakatani and T. Yamanishi, ibid., 34, 1355 (1970).

4) C. P. Natarajan, S. Anandaraman and M. L. Shankaranarayana, Biochem. Rev., XLV, 10 (1974).

5) A. S. L. Tirimanna and $R$ L. Wickremasinghe, Tea $Q ., 36,115$ (1965).

6) G. W. Sanderson, and J. G. Gonzalez, J. Food Sci., 36, 231 (1971).

7) G. W. Sanderson and H. N. Graham, J. Agric. Food Chem., 21, 576 (1973).

8) C. Subbarayan, F. B. Jungalwala and H.R. Cama, Anal. Biochem., 12, 275 (1965).

9) B. H. Davies, in "Chemistry and Biochemistry of Plant Pigments," ed. by T. W. Goodwin, 1965, p. 529 .

10) A. L. Curl and C. F. Bailey, J. Agric. Food Chem., 2, 685 (1954).

11) T. W. Goodwin, in "Modern Methods of Plant Analyses," ed. by K. Peach and M. Tracey, 1955, p. 272.

12) J. E. Ayers, M. J. Fishwick, G. Land and T. Swain, Nature, 203, 81 (1964).

13) R. L. Wickremasinghe, Phytochemistry, 13, 2057 
(1974).

14) E. Muggler-Chavan, R. Viani, J. Bricout and H. E. Robert, Helv. Chim. Acta, 52, 549 (1969).

15) B. K. Koe and L. Zechmeister, Arch. Biochem, Biophys., 46, 100 (1953).

16) P. Karrer and E. Jucker, Helv. Chim. Acta, 28, 300 (1945).

17) C. Subbarayan and H. R. Cama, Ind. J. Chem.,
3, 463 (1965).

18) P. Karrer and E. Jucker, Helv. Chim. Acta, 29, 229 (1946).

19) F. B. Jungalwala and H. R. Cama, Biochem. J., 84, 1 (1962).

20) B. R. Premachandra, J. Jacob and H. R. Cama, Ind. J. Nutr. Diet., 11, 28 (1974). 